RESEARCH ARTICLE

\title{
Antifungal Activity of Arginine-Based Surfactants
}

\author{
M. Elisa Fait ${ }^{1}$, Helen P. S. da Costa $^{2}$, Cleverson D. T. Freitas ${ }^{3}$, Laura Bakás ${ }^{1}$ and Susana R. Morcelle ${ }^{1, *}$
}

${ }^{I}$ Centro de Investigación de Proteinas Vegetales (CIPROVE-CIC), Depto. de Cs. Biológicas, Facultad de Cs. Exactas, Universidad Nacional de La Plata (UNLP), La Plata, Argentina; ${ }^{2}$ Laboratório de Toxinas Vegetais, Depto. de Bioquímica e Biologia Molecular, Universidade Federal do Ceará, Ceará, Brasil; ${ }^{3}$ Laboratório de Biotecnologia de Proteases Vegetais, Depto. de Bioquímica e Biologia Molecular, Universidade Federal do Ceará, Ceará, Brasil

\begin{abstract}
Background: Amino acid based surfactants constitute an important class of surface active biomolecules showing remarkable biocompatible properties. Antimicrobial activity is one of the most remarkable biological properties of this kind of surfactants, which have been widely studied against a broad spectrum of microorganisms. However, the antifungal activity of this kind of compound has been less well investigated. The aim of this work is the study of the antifungal activity of two novel argininebased surfactants $\left(N^{\alpha}\right.$-benzoyl-arginine decylamide, Bz-Arg-NHC 10 and $N^{\alpha}$-benzoyl-arginine dodecylamide, Bz-Arg- $\mathrm{NHC}_{12}$ ), obtained by an enzymatic strategy, against phytopathogenic filamentous fungi and dermatophyte strains.
\end{abstract}

Methods: Four phytopathogenic fungi (Fusarium oxysporum, Fusarium solani, Colletotrichum gloeosporioides and Colletotrichum lindemuthianum) and two human pathogenic fungi (dermatophytes Trichophyton rubrum and Trichophyton mentagrophytes) were tested. Inhibition of vegetative growth and conidia germination was investigated for the phytopathogenic fungi. In order to elucidate the possible mechanism of biocide action, membrane integrity, as well as the production of reactive oxygen species (ROS) were evaluated. Additionally, the inhibition of germination of dermatophyte microconidia due to both arginine-based surfactants was studied. Minimum inhibitory concentration, as well as the concentration that inhibits $50 \%$ of germination were determined for both compounds and both fungal strains.

Results: For the vegetative growth of phytopathogenic fungi, the most potent arginine-based compound was $\mathrm{Bz}-\mathrm{Arg}-\mathrm{NHC}_{10}$. All the tested compounds interfered with the conidia development of the studied species. Investigation of the possible mechanism of toxicity towards phytopathogenic fungi indicated direct damage of the plasma membrane and production of ROS. For the two strains of dermatophyte fungi tested, all the proved compounds showed similar fungistatic efficacy.

Conclusion: Bz-Arg- $\mathrm{NHC}_{10}$ and $\mathrm{Bz}-\mathrm{Arg}-\mathrm{NHC}_{12}$ were demonstrated to have broad biocidal ability against the proliferative vegetative form and the asexual reproductive conidia. Results suggest that both membrane permeabilization and induction of oxidative stress are part of the antifungal mechanisms involved in the interruption of normal conidia development by Bz-Arg- $\mathrm{NHC}_{\mathrm{n}}$, leading to cell death.

Keywords: Arginine-based surfactants, antifungal activity, phytopathogenic fungi, dermatophytes, membrane damage, ROS production.

\section{INTRODUCTION}

Surfactants or tensides consist of a group of molecules of amphiphilic nature, i.e., they have both a hydrophilic and hydrophobic part. This unique structure makes surfactants capable of modifying the properties of a surface or an interface, turning them into multifunctional compounds. They can be used as cleaners, emulsifiers, solubilizers, dispersants

*Address correspondence to this author at the Centro de Investigación de Proteínas Vegetales (CIPROVE-CIC), Depto. de Cs. Biológicas, Facultad de Cs. Exactas, Universidad Nacional de La Plata (UNLP), La Plata, Argentina; Tel: +54 2214230121 ext 57; E-mail: morcelle@biol.unlp.edu.ar and, according to their chemical nature, they can even act as penetration enhancers and/or antimicrobial agents [1]. Such abilities make surfactants one of the major commodities used within several industries, including usage in cleaners, personal care products, pharmaceuticals, food additives, laundry detergents, and lubrication, among many others. The worldwide market for surfactants reached US\$20.29 billion in 2014 , and it is expected to reach a value of US\$28.83 billion by 2023 [2]. Cationic surfactants are amphiphilic compounds which have a hydrophobic tail and a cationic head, and they play an important role as antiseptic agents in cosmetics and other pharmaceutical formulations, such as general biocides, fabric softeners, and hair conditioners, as well as in a number 
of bulk chemical applications [3]. Interestingly, cationic surfactants are expected to experience a progressive growth in the tensides global market during the aforementioned period $[2]$.

Amino acid based surfactants constitute an important class of surface active biomolecules showing remarkable biocompatible properties, such as low toxicity, no irritancy, high biodegradability and a minimal environmental impact [4]. In particular, those bearing a positive net charge can be considered as alternatives to cationic antimicrobial peptides (AMPs), which are produced by all living organisms as components of their innate immune systems; these type of peptides have a polar head consisting of 10-20 amino acids with a positive net charge at physiological $\mathrm{pH}$ and a hydrophobic moiety, and they can be used as models for the design of new antimicrobial agents. Recently, synthetic peptides carrying basic amino acids such as arginine and lysine were demonstrated to have a promising activity against Gram positive bacteria and some strains of Candida spp. [4]. In addition, native lipopeptides are also a group of natural compounds with a peptidic moiety attached to an aliphatic acid. However, both AMPs and native lipopeptides are usually toxic to mammalian cells due to their lack of selectivity [5]. In this sense, synthetic cationic amino acid based surfactants are structurally similar to the native lipopeptides, but have the advantage of being less toxic. This kind of compound has a growing commercial relevance in the world market: Ajinomoto Co., Inc. (Japan) offers a large number of surfactants derived from amino acids for applications ranging from cosmetics to detergents. One notable compound is the arginine-based surfactant LAE ( $N^{\alpha}$-lauroyl arginine ethyl ester), which is a commercial product known as Mirenat ${ }^{\circledR}$ in the food sector and Aminat ${ }^{\circledR}$ in the cosmetic industry and is manufactured by Vedeqsa, Inc. (Spain) $[6,7]$.

Different kinds of arginine-based surfactants have been synthesized and characterized [5,8].Antimicrobial activity is one of the most remarkable biological properties of this family of surfactants, which has been widely studied against a broad spectrum of microorganisms. In this sense, argininebased surfactants have been demonstrated to be especially active against Gram positive bacteria in general [9], whereas others belonging to the same family of compounds showed similar behavior against both Gram positive and Gram negative bacteria [10]. However, antifungal activity of cationic surfactants in general, and arginine-based surfactants in particular, have been less well investigated. The biocidal properties of this kind of compounds against Candida albicans or other pathogenic/opportunistic yeasts have been studied; however, their fungicidal effectiveness towards other fungal species is less well explored [11-17]. The study and finding of novel antifungal compounds is not a minor consideration, since fungal pathogens exert a tremendous influence on animal and plant life, having a strong impact on species extinctions, food security, ecosystem disturbances and human health [18].

In the present work, we tested the antifungal activity of two novel arginine-based surfactants ( $N^{\alpha}$-benzoyl-arginine decylamide, Bz-Arg-NHC ${ }_{10}$ and $N^{\alpha}$-benzoyl-arginine dodecylamide, Bz-Arg-NHC 12 , Fig. 1), obtained by an enzymatic strategy, against four species of phytopathogenic filamentous fungi and two dermatophyte strains. The tested phytopathogenic species are hemibiotrophic fungi responsible for causing different diseases in several crops of economic interest: Fusarium oxysporum and Fusarium solani are cosmopolitan fungal pathogens that produce wilt and cortical rot diseases $[19,20]$, whereas Colletotrichum gloeosporioides and Colletotrichum lindemuthianum are the causal agents of anthracnose disease of fruit and other crops [21, 22]. Dermatophytes are the fungi responsible for the most common fungal diseases in humans, affecting $\sim 25 \%$ of the population worldwide [18]. Since the emergence of multidrug resistance in fungal infections constitutes a major problem and ongoing threat, the continuous search for novel antifungal compounds is a topic of the utmost of importance.

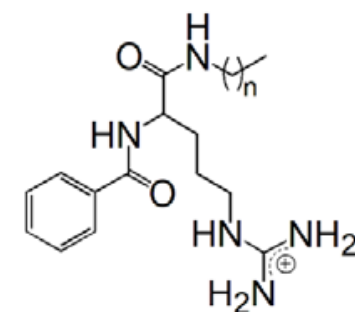

Fig. (1). Molecular structure of arginine derivatives $N^{\alpha}$-benzoylarginine decylamide $\left(\mathrm{Bz}-\mathrm{Arg}-\mathrm{NHC}_{10}, \mathrm{n}=9\right)$ and $N^{\alpha}$-benzoyl-arginine dodecylamide (Bz-Arg-NHC $12, \mathrm{n}=11$ ).

\section{MATERIALS AND METHODS}

\subsubsection{Chemicals}

$N^{\alpha}$-benzoyl-arginine decylamide (Bz-Arg-NHC $\left.\mathrm{N}_{10}\right)$ and $N^{\alpha}$-benzoyl-arginine dodecylamide $\left(\mathrm{Bz}-\mathrm{Arg}-\mathrm{NHC}_{12}\right)$ were synthesized using papain adsorbed onto polyamide, purified and characterized as described elsewhere[10]. Sabouraud Dextrose Agar (SDA), Sabouraud Dextrose Broth 2X (SDB), Potato Dextrose Agar (PDA) and Yeast Peptone Dextrose Broth (YPD) were purchased from Himedia Laboratories (Mumbai, India). Propidiumiodide (PI) waspurchased from Sigma (Brazil). Cetrimide was from Dishman Pharmaceuticals and Chemicals (India). The rest of the chemicals used in this work were of the highest analytical purity commercially available.

The purity and identity of Bz-Arg- $\mathrm{NHC}_{10}$ and Bz-Arg$\mathrm{NHC}_{12}$ were confirmed by ${ }^{1} \mathrm{H}-\mathrm{NMR}$ and ESI MS.

Bz-Arg-NHC $10{ }^{1} \mathrm{H}$ NMR (400 $\left.\mathrm{MHz}, \mathrm{CD}_{3} \mathrm{OD}\right) \delta 7.80-$ 7.76 (m, 2H, Ph, H-2', H-6'), 7.48 - 7.43 (m, 1H, Ph, H-4'), 7.40 - 7.34 (m, 2H, Ph, H-3', H-5'), 4.74 (s, 6H, N트, COCㅌNH), $4.46\left(\mathrm{dd}, J=8.9,5.5 \mathrm{~Hz}, 1 \mathrm{H},(\mathrm{NH})_{2} \mathrm{CHNH}\right), 3.18-$ $3.12\left(\mathrm{~m}, 2 \mathrm{H}, \mathrm{CH}_{3}\left(\mathrm{CH}_{2}\right)_{8} \mathrm{CH}_{2} \mathrm{NHCO}\right), 3.10(\mathrm{t}, J=7.0 \mathrm{~Hz}$, $2 \mathrm{H}), 2.84-2.74(\mathrm{~m}, 1 \mathrm{H}), 1.91-1.80(\mathrm{~m}, 1 \mathrm{H}), 1.79-1.69$ $(\mathrm{m}, 1 \mathrm{H}), 1.68-1.48(\mathrm{~m}, 2 \mathrm{H}), 1.48-1.34(\mathrm{~m}, 2 \mathrm{H}), 1.33-$ $1.11(\mathrm{~m}, 18 \mathrm{H}), 1.10-1.03(\mathrm{~m}, 1 \mathrm{H}), 0.79\left(\mathrm{~m}, 4 \mathrm{H}, \mathrm{CH}_{3}, \mathrm{~N} \underline{\mathrm{H}}\right)$.

Bz-Arg- $\mathrm{NHC}_{12}{ }^{1} \mathrm{H}$ NMR (400 $\left.\mathrm{MHz}, \mathrm{CH}_{3} \mathrm{OD}\right) \delta 7.88-$ 7.85 (m, 2H, Ph, H-2', H-6'), 7.58 - 7.50 (m, 1H, Ph, H-4'), 7.46 (ddt, $J=8.2,6.7,1.3 \mathrm{~Hz}, 2 \mathrm{H}, \mathrm{Ph}, \mathrm{H}-3$ ', H-5'), 4.83 (s, $6 \mathrm{H}, \mathrm{N} \underline{\mathrm{H}}, \mathrm{COC} \underline{\mathrm{HNH}}), 4.54(\mathrm{dd}, J=8.9,5.7 \mathrm{~Hz}, 1 \mathrm{H}$, $\left.(\mathrm{NH})_{2} \mathrm{CHNH}\right), 3.28-3.10(\mathrm{~m}, 2 \mathrm{H}), 2.89(\mathrm{t}, J=7.0 \mathrm{~Hz}, 1 \mathrm{H})$, $2.02-1.56(\mathrm{~m}, 6 \mathrm{H}), 1.49(\mathrm{dd}, J=13.8,6.9 \mathrm{~Hz}, 2 \mathrm{H}), 1.40-$ $1.22(\mathrm{~m}, 20 \mathrm{H}), 1.16(\mathrm{t}, J=7.1 \mathrm{~Hz}, 1 \mathrm{H}), 0.87(\mathrm{t}, J=6.8 \mathrm{~Hz}$, $\left.3 \mathrm{H}, \mathrm{CH}_{3}\right)$. 
Theoretical exact masses were calculated using the ChemCalc online service according to Patiny and Borel [23], and compared with those obtained by ESI MS. Bz-Arg$\mathrm{NHC}_{10}$, ESI (+)-TOF-MS [M+1] calculated for $\mathrm{C}_{23} \mathrm{H}_{40} \mathrm{~N}_{5} \mathrm{O}_{2}$ : 418.31820; found: 418.31889. Bz-Arg-NHC ${ }_{12}$, ESI (+)-TOFMS [M+1] calculated for $\mathrm{C}_{25} \mathrm{H}_{44} \mathrm{~N}_{5} \mathrm{O}_{2}: 446.34950$; found: 446.34924 .

\subsubsection{Microorganisms}

The antifungal activity of the surfactants was tested against several fungi strains. Phytopathogenic fungi isolates (F. oxysporum, F. solani, C. gloeosporioides and C. lindemuthianum) were provided by the Laboratory of Plant Defense Proteins (Laboratório de ProteínasVegetais de Defesa) at the Department of Biochemistry and Molecular Biology at the Federal University of Ceará, whereas the dermatophyte isolates (Trichophyton rubrum and Trichophyton mentagrophytes) were obtained from the local collection of the Laboratory of Plant Toxins (Laboratório de Toxinas Vegetais), also at the Federal University of Ceará. All isolates were maintained on SDA at $28^{\circ} \mathrm{C}$ and $70 \%$ of relative humidity, in the absence of light.

\subsubsection{Preparation of Inoculum Suspensions}

Stock inoculums of fungi were obtained from 2 to 3 week-old cultures grown on PDA at $28^{\circ} \mathrm{C}$ to induce sporulation. In the case of the phytopathogenic strains, fungal colonies were covered with $5 \mathrm{~mL}$ of sterile distilled water, the surface was gently scraped with a sterile loop and the resultant mixtures were filtered through a sterile cloth to remove hyphae. Conidia were quantified for each stock suspension using a Neubauer chamber with the aid of a BX60 Olympus light microscope. Conidia suspensions were diluted in sterile distilled water to the concentration indicated in each assay. For the preparation of stock inoculums of the dermatophyte isolates, colonies were covered with $5 \mathrm{~mL}$ of sterile saline solution $(\mathrm{NaCl} 0.85 \% \mathrm{w} / \mathrm{v})$, vigorously shaken using a vortex and the resultant mixtures were filtered through a sterile cotton-wool filter in order to remove hyphae. Turbidity of each final inoculum suspension was determined spectrophotometrically at $530 \mathrm{~nm}$ (Genesys $10 \mathrm{~S}$ UV-Vis, Thermo Scientific, USA). Working dilutions of the microconidia suspensions were prepared in sterile saline solution in order to reach the concentration indicated for each assay.

\subsubsection{Preparation of the Surfactant Solutions}

Stock solutions of the surfactants $(50 \mathrm{mM})$ were prepared in DMSO, sterilized by filtration and stored at $-20^{\circ} \mathrm{C}$. Dilutions of these solutions were prepared using sterile nanopure water or culture medium as indicated in each assay.

\subsection{Antifungal Assays}

\subsubsection{Inhibition of Vegetative Growth Assay}

The inhibitory effect of Bz-Arg- $\mathrm{NHC}_{10}$ and Bz-Arg$\mathrm{NHC}_{12}$ on the mycelia growth of phytopathogenic fungi were contrasted to that of Cetrimide using 96-well flat-bottom microtiter plates (Kartell, Italy) [24]. Serial dilutions of the surfactant stock solutions were prepared in a range of concentrations from 6.25 to $800 \mu \mathrm{M}$, using sterile nanopure water as solvent. Initially, each well of the plates was filled with $90 \mu \mathrm{L}$ of YPD $2 \mathrm{X}$ and $10 \mu \mathrm{L}$ of the conidia suspension prepared in nanopure water $\left(2 \times 10^{5} \mathrm{conidia} / \mathrm{mL}\right)$ was added, followed by incubation at $28^{\circ} \mathrm{C}$ and $70 \%$ relative humidity in the absence of light. After $16 \mathrm{~h}, 100 \mu \mathrm{L}$ of the surfactant dilutions previously prepared were added to the wells. Hyphae incubated in presence of $\mathrm{H}_{2} \mathrm{O}_{2}(100 \mathrm{mM})$ and YPD served as negative and positive growth controls, respectively. All plates were sealed and incubated at $28^{\circ} \mathrm{C}$ and $70 \%$ relative humidity for $72 \mathrm{~h}$, in the absence of light. Optical density at $630 \mathrm{~nm}\left(\mathrm{OD}_{630}\right)$ was measured periodically using an automated microplate reader (Biotrak II Plate Reader, Amersham Biosciences). Antifungal activity was expressed as the percentage of growth inhibition (GI\%) calculated by comparison with control wells (the mean optical density of untreated cells was set to $100 \%$ viability). Whenever possible the $\mathrm{IC}_{50}$ (concentration of surfactant causing $50 \%$ death of the hyphae population or, similarly, at which $50 \%$ of the hyphae are viable relative to the control) were calculated from the concentration-growth inhibition curves by fitting data sets to a Boltzmann-type sigmoid model using the OriginPro $8^{\circledR}$ software. In all cases, data were presented as the mean $\pm \mathrm{SD}$ of three independent replicate determinations.

\subsubsection{Inhibition of Conidia Germination Assay}

The effect of Bz-Arg-NHC 10 and Bz-Arg-NHC 12 on the germination of phytopathogenic conidia was evaluated according to the methodology described by Ji and Kúc [25], adapted to use reticulated polystyrene plates (J. Prolab, São José dos Pinhais, Paraná, Brazil). In each case, $10 \mu \mathrm{L}$ of the conidia aqueous suspension $\left(2 \times 10^{5}\right.$ conidia $\left./ \mathrm{mL}\right)$, prepared in nanopure water as described in the methodology section, was added to $10 \mu \mathrm{L}$ of the surfactant solution $(0.8 \mathrm{mM})$ prepared in nanopure water. Conidia incubated with nanopure water or $\mathrm{H}_{2} \mathrm{O}_{2}(100 \mathrm{mM})$ were used as negative and positive controls for the inhibition of the conidia germination, respectively. Cetrimide $(0.8 \mathrm{mM})$, a commercial cationic surfactant, was also included as a control. All plates were closed and sealed to avoid evaporation and incubated at $28^{\circ} \mathrm{C}$ and $70 \%$ relative humidity for $24 \mathrm{~h}$, in the absence of light. After incubation, conidia germination was examined visually using a BX60 Olympus light microscope. Conidia were considered germinated if any hyphae structures were present. For each experiment, three replicate samples were tested.

\subsubsection{Evaluation of Membrane Integrity}

Conidia suspensions of $C$. lindemuthianum $(25 \mu \mathrm{L}$; $10^{7}$ conidia $/ \mathrm{mL}$ ) were incubated with $25 \mu \mathrm{L}$ of the surfactant solutions $(0.8 \mathrm{mM})$ prepared in water as described previously, for $30 \mathrm{~min}$ at $25^{\circ} \mathrm{C}$. Membrane integrity was evaluated by the addition of $5 \mu \mathrm{L}$ of propidium iodide (PI, $0.1 \mathrm{mM}$ ), observing the uptake of the fluorescence probe after $30 \mathrm{~min}$ of incubation at $25^{\circ} \mathrm{C}$, using a fluorescence microscope (Nikon Eclipse 80i) with $\lambda_{\text {ex }} 540 \mathrm{~nm}$ and $\lambda_{\text {em }} 608 \mathrm{~nm}[26]$. Conidia that fluoresced red after incubation with PI were classified as damaged, unstained cells as intact. Each experiment was performed twice, consisting of two replicates per treatment.

\subsubsection{In Situ Detection of Reactive Oxygen Species}

In situ production of reactive oxygen species (ROS), such as $\mathrm{H}_{2} \mathrm{O}_{2}$, by conidia of $F$. oxysporum and $C$. gloeosporioides 
treated with the surfactants was assessed by the addition of 3,3'-diaminobenzidine (DAB) [27]. In the presence of peroxidases and $\mathrm{H}_{2} \mathrm{O}_{2}$, DAB forms a dark brownish precipitate, causing a visible cytochemical stain. During the assay, $25 \mu \mathrm{L}$ of the conidia suspension $\left(10^{7}\right.$ conidia $\left./ \mathrm{mL}\right)$ was incubated with $25 \mu \mathrm{L}$ of the surfactant solution $(0.8 \mathrm{mM})$ prepared in water as described previously, for $30 \mathrm{~min}$ at $28^{\circ} \mathrm{C}$ and $70 \%$ relative humidity. After the addition of $10 \mu \mathrm{L}$ of the DAB solution $(1 \mathrm{mg} / \mathrm{mL})$, the mixture was incubated for $2 \mathrm{~h}$ in the same conditions. Formation of the dark brownish precipitate was observed with the aid of a BX60 Olympus light microscope.

\subsubsection{Inhibition of Dermatophyte Microconidia Germina- tion Assay}

The effect of the surfactants was also assessed on the germination of dermatophyte microconidia according to the methodology previously described [28] with some adaptations. Assays were carried out using 96-well flat-bottom microtiter plates (Global Plast, Global Trade Technology, Brazil). Serial dilutions of the surfactant stock solutions were prepared in a range of concentrations from 7.8 to $1000 \mu \mathrm{M}$, using sterile SDB doubled concentrated (2X) as solvent. In each well, $100 \mu \mathrm{L}$ of the surfactant solution was added to $100 \mu \mathrm{L}$ of the microconidia suspension prepared in sterile saline solution as described previously and adjusted to reach a final turbidity of $0.08-0.1$ adsorption at $530 \mathrm{~nm}$. Microconidia incubated in presence of $\mathrm{H}_{2} \mathrm{O}_{2}(100 \mathrm{mM})$ and SBD served as negative and positive growth controls, respectively. Sterility controls were also included. All plates were sealed and incubated at $28^{\circ} \mathrm{C}$ and $70 \%$ relative humidity for 21 days, in the absence of light. From the seventh day onwards, $\mathrm{OD}_{630}$ was measured periodically using an automated microplate reader (Biotrak II Plate Reader, Amersham Biosciences). For each surfactant concentration, the percentage of growth inhibition (GI\%) compared with control wells (the mean optical density of untreated microconidia was set to $100 \%$ viability) was calculated for 7 and 21 days of incubation [29-31]. At these incubation times, the minimum inhibitory concentration (MIC) values were established, considering the MIC as the lowest surfactant concentration able to completely inhibit fungal growth $(\mathrm{GI} \%=100 \%)$. In addition, for the 21 st incubation day, the $\mathrm{IC}_{50}$ (concentration of surfactant causing 50\% inhibition of mycelial development relative to the control) for each surfactant and each isolate strain was calculated from the concentration-response curves by fitting data sets to a Boltzmann-type sigmoid model using the
OriginPro $8^{\circledR}$ software. In all cases, data were presented as the mean $\pm \mathrm{SD}$ of three independent replicate determinations.

\section{RESULTS AND DISCUSSION}

\subsection{Investigation of Arginine-Based Surfactants Activity Against Phytopathogenic Fungi}

For this particular group of pathogens, antifungal assays were performed over the proliferative vegetative form (hyphae) and the asexual reproductive conidia. Investigation of the possible antifungal mechanism of surfactants was made through the analysis of their effect on the fungal membrane integrity.

\subsubsection{Inhibition of Vegetative Growth}

All the tested compounds exhibited antifungal activity against the four phytopathogenic isolates analyzed (Table 1). Even in the case of $F$. oxysporum treated with Bz-Arg$\mathrm{NHC}_{12}$, for which the determination of the $\mathrm{IC}_{50}$ value was not possible (the data obtained could not be fitted to the typical sigmoidal curve), the inhibitory effect of vegetative growth was still observed (Fig. 2). In general, Bz-Arg$\mathrm{NHC}_{10}$ was demonstrated to be more effective than its counterpart with 12 carbon atoms in the hydrophobic tail, it also exhibited equivalent or even lower $\mathrm{IC}_{50}$ values than the commercial cationic surfactant Cetrimide in all cases. This behavior was also reported for gemini quaternary ammonium salts having alkyl chain arrangements of the betaine based ester type against pathogenic yeasts (C. albicans and Rhodotorula mucilaginosa) [11]. Nevertheless, F. solani growth was more effectively inhibited by $\mathrm{Bz}-\mathrm{Arg}-\mathrm{NHC}_{12}$. This last result is in agreement with those obtained for other argininebased surfactants when tested against bacteria: the longer the alkyl chain of the arginine-based surfactant, the more effective its antimicrobial activity [32]. However, the antifungal potency of each compound appears to be more dependent on the nature of its interaction with each fungus in particular (i.e., with its cell wall and/or plasma membrane) rather than exclusively on its chemical structure.

\subsubsection{Inhibition of Conidia Germination}

Conidia are survival structures produced by some organisms (such as bacteria, fungi and protozoa) under adverse conditions in order to be dispersed into new environments. Some of the most environmentally resistant eukaryotic conidia are those belonging to fungal species. Conidia, after remaining metabolically quiescent, can rapidly revert from

Table 1. Inhibitory effect of the surfactants on the mycelial growth of phytopathogenic fungi expressed in terms of $\mathrm{IC}_{50}(\mu \mathrm{M})$.

\begin{tabular}{|c|c|c|c|}
\hline \multirow{2}{*}{ Microorganism } & \multicolumn{3}{|c|}{ IC $_{\mathbf{5 0}}{ }^{\mathbf{a}}(\boldsymbol{\mu M})$} \\
\cline { 2 - 4 } & Bz-Arg-NHC $_{\mathbf{1 0}}$ & Bz-Arg-NHC $_{\mathbf{1 2}}$ & Cetrimide $^{2}$ \\
\hline \hline C. gloeosporioides & $61.3 \pm 15.9$ & $168.2 \pm 10.6$ & $73.2 \pm 2.9$ \\
\hline C. lindemuthianum & $44.8 \pm 2.0$ & $80.3 \pm 3.5$ & $79.1 \pm 5.7$ \\
\hline F. oxysporum & $70.7 \pm 5.9$ & ND & $60.8 \pm 7.4$ \\
\hline F. solani & $61.6 \pm 3.6$ & $21.6 \pm 3.2$ & $67.9 \pm 17.4$ \\
\hline
\end{tabular}

${ }^{\mathrm{a}} \mathrm{IC}_{50} \pm \mathrm{SD}$; concentration values that cause $50 \%$ death of the hyphae population or, similarly, at which $50 \%$ of the hyphae are viable relative to the control after $72 \mathrm{~h}$ of exposure to the surfactants. ND = not determined. 
a)

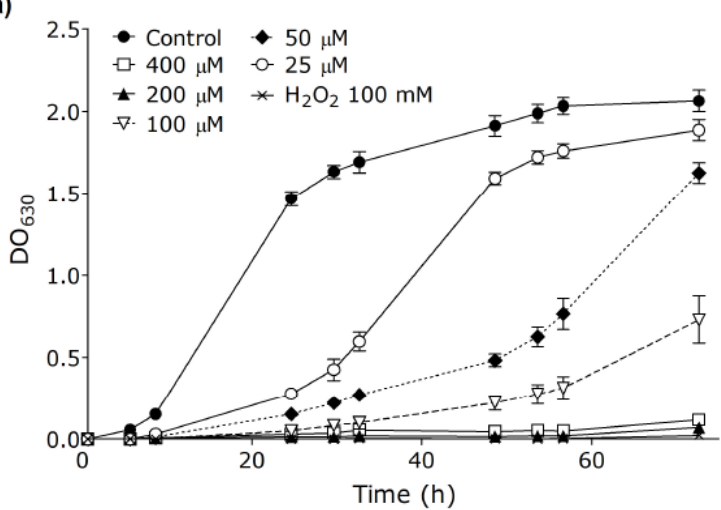

b)

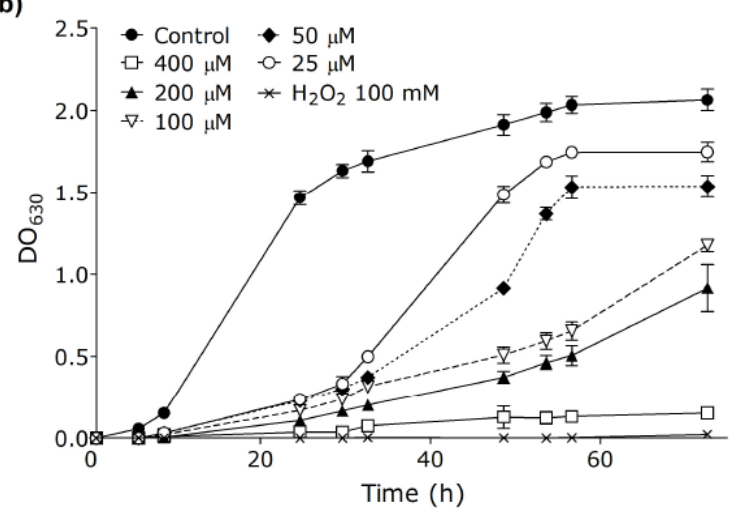

Fig. (2). Growth kinetics of Fusarium oxysporuminYPD broth added with (a) Bz-Arg-NHC 10 or (b) Bz-Arg-NHC 12 , at different concentrations. Values are plotted as the mean $\pm \mathrm{SD}$.

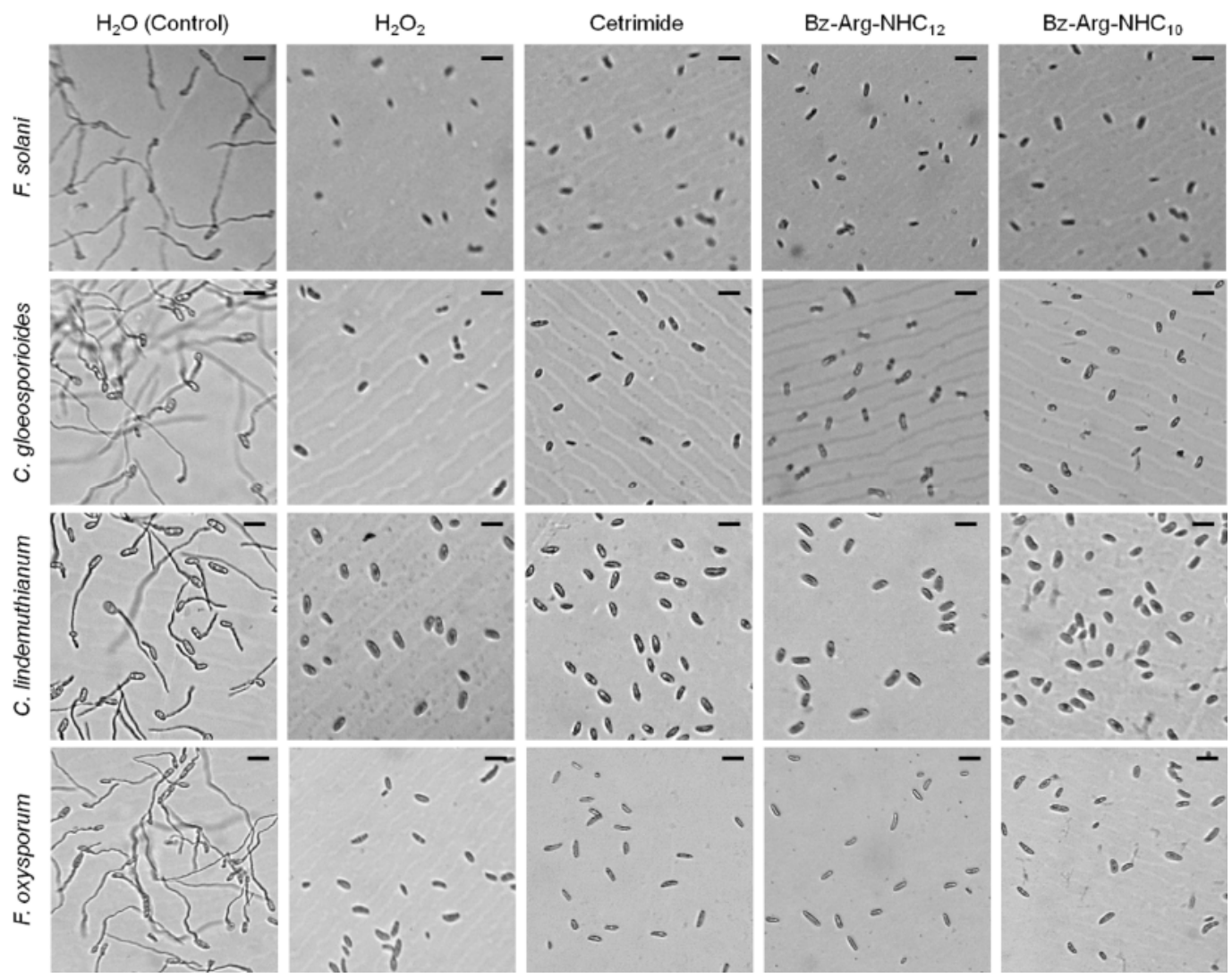

Fig. (3). Inhibition of conidia germination produced by the exposure to $\mathrm{Bz}-\mathrm{Arg}-\mathrm{NHC}_{10}, \mathrm{Bz}-\mathrm{Arg}-\mathrm{NHC}_{12}$ or Cetrimide ( $\left.400 \mu \mathrm{M}\right)$ compared to controls (water and $\mathrm{H}_{2} \mathrm{O}_{2}$ were used as negative and positive controls for the inhibition, respectively). Bars: $50 \mu \mathrm{m}$.

dormancy and germinate to resume vegetative growth whenever external conditions are appropriate for fungal growth [33].

We further investigated the effect of the two argininebased surfactants on conidia germination, comparing it to that observed for Cetrimide. As can be seen in Fig. (3), all surfactants inhibited conidia germination of all the fungal isolates studied, demonstrating that the three compounds were capable not only of inhibiting the vegetative growth of the phytopathogenic fungi, but also affected conidia development. Since it is generally considered that antifungal compounds should preferably prevent germination of conidia, because this is the first event of the asexual life cycle of this kind of fungi [34], an investigation of the fungicidal mechanism was performed.

\subsubsection{Mechanism of Arginine-Based Surfactant Antifungal Activity Against Phytopathogenic Fungal Conidia}

\subsubsection{Evaluation of Membrane Integrity}

It is generally accepted that AMPs and native lipopeptides exert their antimicrobial activity by association with cell membranes, causing depolarization, lysis and cell death by disruption of the lipid bilayer [5]. Bearing this in mind, both membrane integrity and conidia viability were assessed using an impermeant fluorescent probe and fluorescence microscopy. In this study, we measured the uptake of propid- 
ium iodide (PI) by conidia of $C$. lindemuthianum treated with Bz-Arg-NHC 10, Bz-Arg-NHC 12 or Cetrimide. PI is a fluorescent dye that binds to DNA and works as a dye-exclusion viability probe, as it is unable to penetrate the membrane of living cells but is capable of passing through that of nonviable cells, causing their fluorescent staining [35]. The uptake of PI in conidia treated with the surfactants was evidenced by the appearance of intense red fluorescence (Fig. 4), whereas no fluorescence was observed in the absence of them (control).
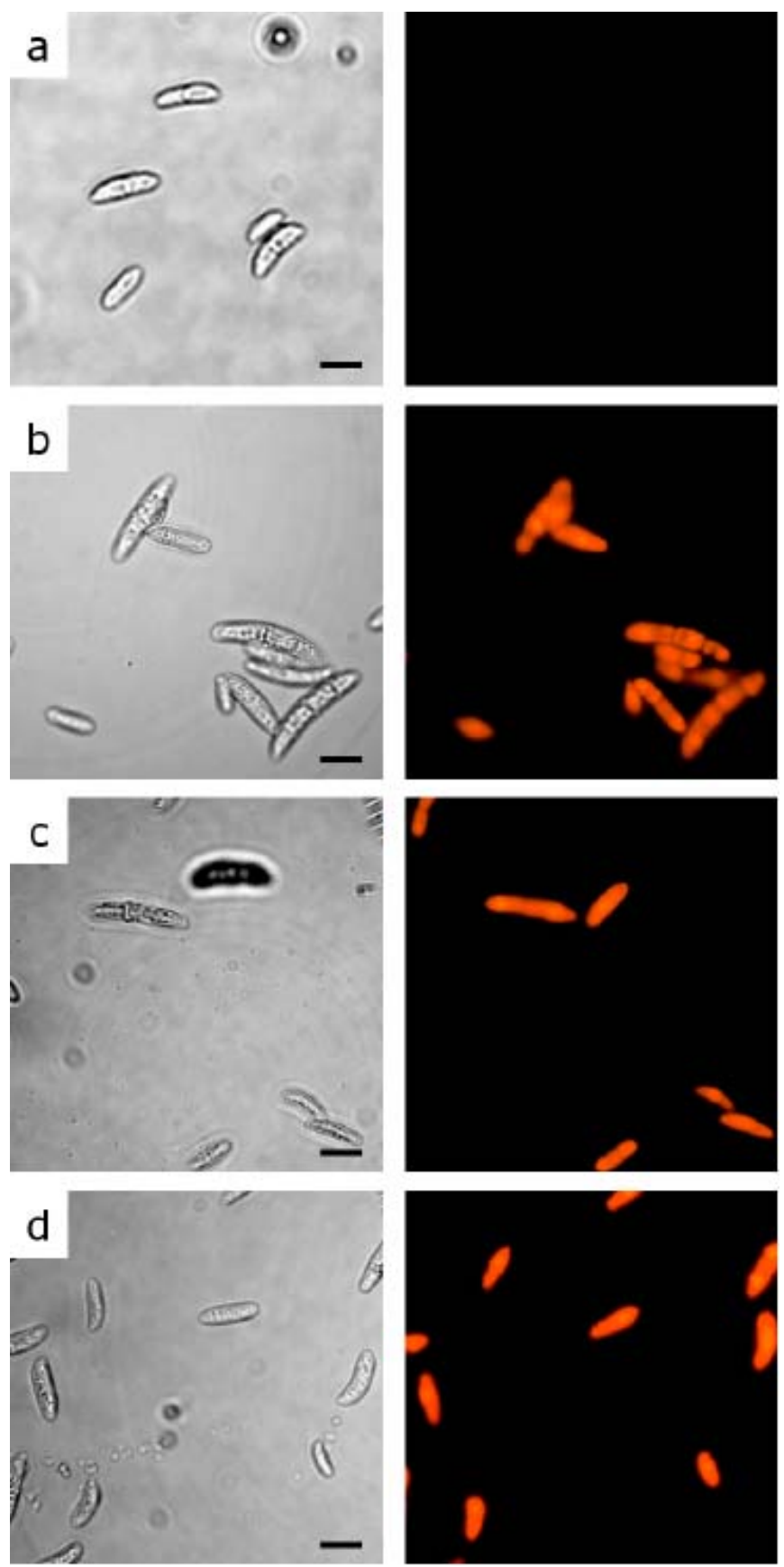

Fig. (4). Membrane permeabilization induced in conidia of Colletotrichum lindemuthianum by the exposure to (b) Bz-Arg- $\mathrm{NHC}_{12}$ $400 \mu \mathrm{M}$, (c) Bz-Arg-NHC $10400 \mu \mathrm{M}$ or (d) Cetrimide $400 \mu \mathrm{M}$, compared to control in absence of the surfactants (a). Bars: $10 \mu \mathrm{m}$.
As described above, the hypothetical mechanisms to explain the antimicrobial action of cationic surfactants traditionally include the disruption of cell membranes, involving the leakage of intracellular $\mathrm{K}^{+}$and other ions: this idea has been proved for chlorhexidine and other arginine-based gemini surfactants in bacteria [17]. However, other authors suggested that the critical phenomenon responsible for the antifungal effect of cationic compounds is the reversal of cell charge from negative to positive $[14,36]$. This conclusion is mainly based on the observation that CTAB (one of the main components of Cetrimide, cetyltrimethylammonium bromide) and other cationic surfactants killed C. albicans cells in lower concentrations than their critical micellar concentration (CMC), avoiding disruption of the cell membrane and cellular lysis. Furthermore, a combination of both mechanisms has been also suggested [5]: 1) attachment of cationic molecules to the negative charged cell walls via electrostatic bonds, and 2) interaction of the surfactant alkyl moiety with the membrane lipids, altering the membrane structure.

\subsubsection{In Situ Detection of Reactive Oxygen Species}

As described in the previous section, the electrostatic interaction of cationic surfactants with the negative charged cell surface, as well as their hypothetical insertion in the membrane lipid bilayer, could be two factors that determine antifungal activity. Another possibility that could be considered is a direct effect of surfactants in the cytoplasm: molecules could translocate across the membrane, reach the cytoplasm and interact with its components, altering their activities [37]. In this sense, surfactants could interfere with normal intracellular processes, including cellular respiration. Nakata et al. [38] demonstrated that CTAB, induced oxidative stress in Escherichia coli, by generating superoxide and hydrogen peroxide after exposure to sublethal concentrations of this compound. These authors also demonstrated that superoxide dismutase decreased its activity after treatment of a wild type E. coli strain with CTAB. Additionally, Yu et al. [39] reported that CTAB caused severe mitochondrial membrane depolarization in $C$. albicans, leading to mitochondrial dysfunction: if this effect is produced by reactive oxygen species or by the surfactants per se is still a topic of debate.

Investigations have established the role of ROS, such as $\mathrm{H}_{2} \mathrm{O}_{2}$, as mediators of intracellular signaling cascades. However, excessive production of ROS, due to their high reactivity, may lead to oxidative stress, mitochondrial damage (as above described), loss of cell function and ultimately apoptosis [40]. Taking this into account, we investigated the oxidative stress related to the antifungal activity of Bz-Arg$\mathrm{NHC}_{10}$ and $\mathrm{Bz}-\mathrm{Arg}-\mathrm{NHC}_{12}$ by estimating qualitative ROS production in conidia of C. gloeosporioides and $F$. oxysporum treated with the surfactants. The in situ production of ROS was evidenced by the uptake of the substrate 3,3diaminobenzidine. This compound polymerizes instantly and locally as soon as it comes in contact with ROS in the presence of peroxidase activity, forming a reddish-brown polymer detectable through microscopic observation [27]. As can be seen in Fig. (5), formation of the dark brownish precipitate was not detected in conidia treated with water (control), indicating low levels of $\mathrm{H}_{2} \mathrm{O}_{2}$ in conidia. However, when conidia were previously incubated with the surfactants, they exhibited dark reddish-brown staining, evidencing ROS pro- 

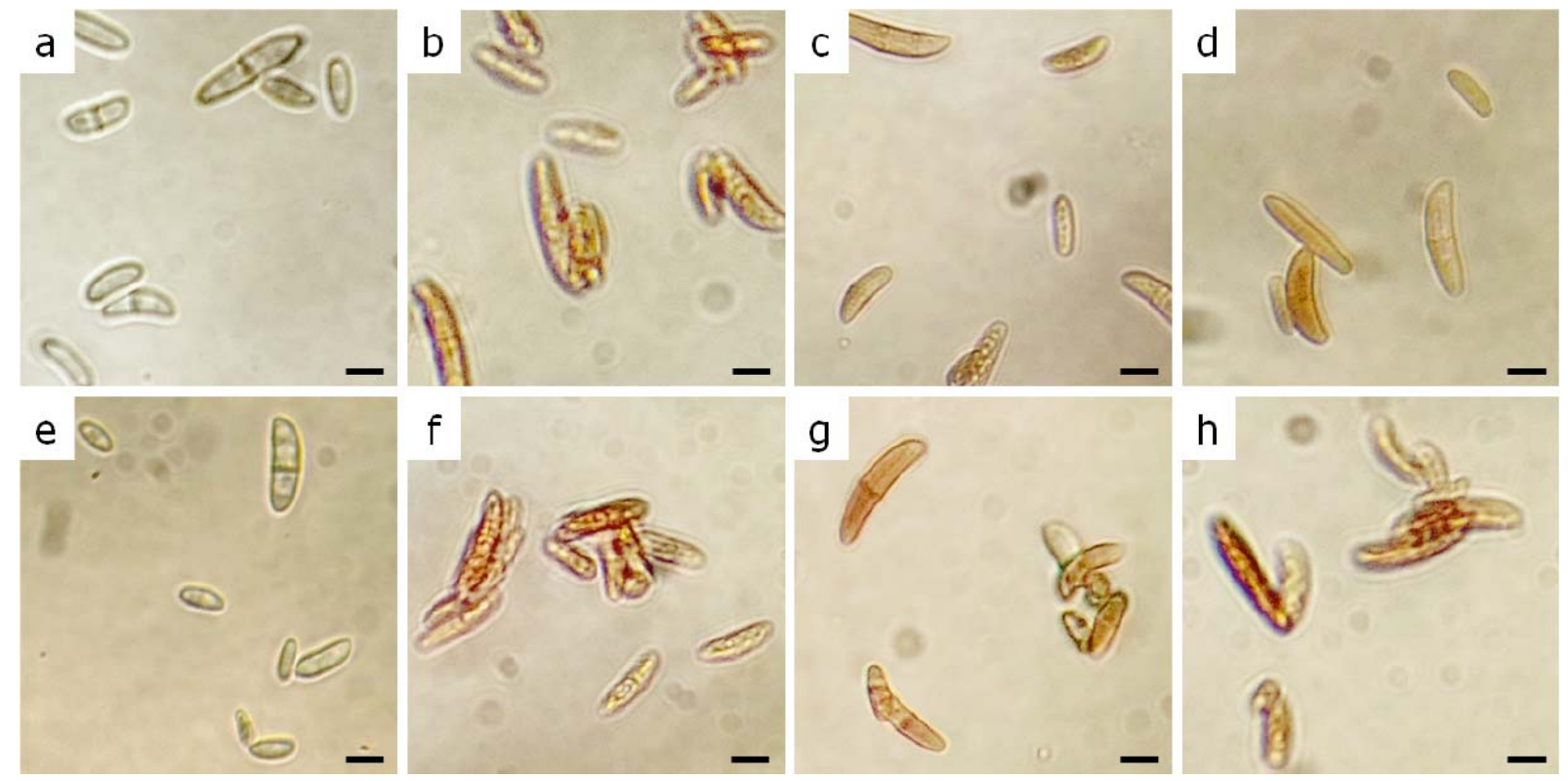

Fig. (5). Detection of reactive oxygen species (ROS) produced in conidia of Colletotrichum gloeosporioides (a-d) and Fusarium oxysporum (e-h), induced by the exposure to Bz-Arg-NHC $10400 \mu \mathrm{M}$ (b, f), Bz-Arg-NHC $12400 \mu \mathrm{M}$ (c, g) or Cetrimide $400 \mu \mathrm{M}$ (d, h) compared to control in absence of the surfactants (a, e). Bars: $10 \mu \mathrm{m}$.

duction. These results suggest that induction of oxidative stress could be part of the antifungal mechanism involved in the interruption of normal conidia development by the surfactants, at least at the concentration tested.

\subsection{Effect of Arginine-Based Surfactants on Human Pathogenic Fungi}

Considering the importance of fungal infections in general, and superficial mycosis in particular, we tested the effect of the arginine-based surfactants we synthesized and Cetrimide against two Trichophyton species (filamentous fungi).

\subsubsection{Inhibition of Dermatophytemicroconidia Germina- tion}

Due to the importance of proper conidia germination in pathogenesis of dermatophytosis, we studied the interference of the process caused by Bz-Arg- $\mathrm{NHC}_{10}$ and $\mathrm{Bz}-\mathrm{Arg}$ $\mathrm{NHC}_{12}$, and compared it to that of Cetrimide. Germination of microconidia of T. rubrum and T. mentagrophytes in SDB with different concentrations of the surfactants added was monitored spectrophotometrically during a total incubation period of 21 days, establishing MIC values for the 7 th and 21st days of incubation. Table 2 summarizes the MIC values obtained together with the $\mathrm{IC}_{50}$ values determined for the maximum incubation period. It can be seen that all three surfactants were able to inhibit both tested strains, exhibiting similar MIC values. As incubation time can influence the MIC determination, we compared the MICs registered for the 7th and 21st days of incubation. Interestingly, the incubation time did not influence the MIC values obtained in most cases. However, in the cases of $T$. rubrum incubated in the presence of Bz-Arg- $\mathrm{NHC}_{12}$ and Cetrimide, analysis of the results revealed that an increased incubation time of 21 days compared to 7 days increases MICs twofold.
As mentioned in the introduction section, the activity of cationic surfactants against molds is not well explored. The antifungal activity of gemini compounds, such as the commercial disinfectant chlorhexidine and others belonging to the same family of bis-(phenylacetyl)-arginine derivatives $\mathrm{C}_{\mathrm{n}}(\mathrm{CA})_{2}$ ( $\mathrm{n}$ being the number of methylene groups in the alkanediamine spacer), was tested against $T$. mentagrophytes [17]. All these compounds showed MIC values ranging from $14 \mu \mathrm{M}$ (chlorhexidine) up to $312 \mu \mathrm{M}\left[\mathrm{C}_{10}(\mathrm{CA})_{2}\right]$ after exposure of 48-72 $\mathrm{h}$ to the antimicrobial agent. In our case, BzArg- $\mathrm{NHC}_{\mathrm{n}}$ and Cetrimide showed MIC values that fall within the same range (see Table 2), the MICs for Bz-Arg$\mathrm{NHC}_{\mathrm{n}}$ being closer to the value obtained for $\mathrm{C}_{12}(\mathrm{CA})_{2}(149$ $\mu \mathrm{M})$, whereas Cetrimide's MIC was of the order of that of $\mathrm{C}_{3}(\mathrm{CA})_{2}(21 \mu \mathrm{M})[17]$.

In the case of our compounds, it has been observed in bacteria that the longer the alkyl chain, the stronger the antimicrobial activity in case of bacteria [10]. However, their fungistatic activity is not so dependent on the alkyl chain size, since both compounds showed similar MIC values.

\section{CONCLUSIONS}

The antifungal activity of Bz-Arg- $\mathrm{NHC}_{10}$ and Bz-Arg$\mathrm{NHC}_{12}$ was proved against phytopathogenic filamentous and dermatophyte fungal isolates. Both compounds were demonstrated to have broad biocidal ability against the proliferative vegetative form (hyphae) and the asexual reproductive conidia. This last finding is particularly interesting since one of the most effective approaches for the interruption of the infectious process is interfering in proper conidia germination, a key step in fungal pathogenesis. Furthermore, in order to gain insights about the antifungal mechanisms of the surfactants, investigations using phytopathogenic conidia were performed. The analysis of the fungal membrane integrity and the qualitative production of ROS could suggest that both membrane permeabilization and induction of oxidative 
Table 2. Inhibitory effect of the surfactants on germination of dermatophyte microconidia expressed in terms of minimum inhibitory concentration (MIC) and $\mathrm{IC}_{50}($ both in $\mu \mathrm{M})$.

\begin{tabular}{|c|c|c|c|c|c|c|c|c|c|}
\hline \multirow{3}{*}{ Microorganism } & \multicolumn{9}{|c|}{ Compound } \\
\hline & \multicolumn{3}{|c|}{ Bz-Arg-NHC ${ }_{10}$} & \multicolumn{3}{|c|}{ Bz-Arg-NHC ${ }_{12}$} & \multicolumn{3}{|c|}{ Cetrimide } \\
\hline & $\begin{array}{c}\mathrm{MIC}_{7}{ }^{\mathrm{a}} \\
(\mu \mathrm{M})\end{array}$ & $\begin{array}{c}\mathrm{MIC}_{21}{ }^{\mathrm{a}} \\
(\mu \mathrm{M})\end{array}$ & $\begin{array}{l}\mathrm{IC}_{50}^{\mathrm{b}} \\
(\boldsymbol{\mu M})\end{array}$ & $\begin{array}{c}\mathrm{MIC}_{7}^{\mathrm{a}} \\
(\mu \mathrm{M})\end{array}$ & $\begin{array}{c}\mathrm{MIC}_{21}{ }^{\mathrm{a}} \\
(\mu \mathrm{M})\end{array}$ & $\begin{array}{l}\mathrm{IC}_{50}^{\mathrm{b}} \\
(\boldsymbol{\mu M})\end{array}$ & $\begin{array}{c}\mathrm{MIC}_{7}^{\mathrm{a}} \\
(\mu \mathrm{M})\end{array}$ & $\begin{array}{c}\mathrm{MIC}_{21}{ }^{\mathrm{a}} \\
(\mu \mathrm{M})\end{array}$ & $\begin{array}{l}\mathrm{IC}_{50}^{\mathrm{b}} \\
(\mu \mathrm{M})\end{array}$ \\
\hline T. rubrum & 125.0 & 125.0 & $52.06 \pm 4.52$ & 62.5 & 125.0 & $32.39 \pm 0.26$ & 62.5 & 125.0 & $51.48 \pm 1.59$ \\
\hline T. mentagrophytes & 125.0 & 125.0 & $58.15 \pm 0.45$ & 125.0 & 125.0 & $57.85 \pm 0.70$ & 62.5 & 62.5 & $37.19 \pm 1.58$ \\
\hline
\end{tabular}

${ }^{\mathrm{a}}$ Lowest surfactant concentration able to completely inhibit fungal growth $\left(\mathrm{OD}_{630}=0\right.$ and $\left.\mathrm{GI} \%=100 \%\right)$ after 7 (MIC 7 ) or 21 (MIC $\left.\mathrm{M}_{21}\right)$ days of exposure to the surfactants. ${ }^{\mathrm{b}} \mathrm{Mean} \pm$ $\mathrm{SD}$; concentration values that cause $50 \%$ inhibition of mycelial development relative to the control after 21 days of exposure to the surfactants ( $\mathrm{IC}_{50}$ ).

stress are part of the antifungal mechanisms involved in the interruption of normal conidia development by Bz-Arg$\mathrm{NHC}_{\mathrm{n}}$. A possible fungicidal mechanism can be postulated: surfactants could produce an alteration of the plasma membrane permeability (as evidenced by the PI assay) without cellular lysis; and this altered permeability could be responsible for increased oxygen permeation with a heightened ROS formation, leading to cell death.

ETHICS APPROVAL AND CONSENT TO PARTICIPATE

Not applicable.

\section{HUMAN AND ANIMAL RIGHTS}

No Animals/Humans were used for studies that are base of this research.

\section{CONSENT FOR PUBLICATION}

Not applicable.

\section{CONFLICT OF INTEREST}

The authors declare no conflict of interest, financial or otherwise.

\section{ACKNOWLEDGEMENTS}

The financial support of MINCyT (PICT 2013-00647), CAPES-MINCyT (017/2014) and UNLP (X11-682) are acknowledged. MEF was awarded a postdoctoral CONICET fellowship. SRM is member of CONICET Researcher Career. LB is member of CICPBA Researcher Career.

\section{REFERENCES}

[1] Lukic, M.; Pantelic, I.; Savic, S. An Overview of Novel Surfactants for Formulation of Cosmetics with Certain Emphasis on Acidic Active Substances. Tenside Surf. Det. 2016, 53, 7-19.

[2] Surfactants (Anionic, Cationic, Non-ionic, Amphoteric, and Others) Market for Household Detergents, Personal Care, Industrial \& Institutional Care, Food Processing, Oilfield Chemicals, Textile \& Leather, and Other Applications - Global Industry Analysis, Size, Share, Growth, Trends and Forecast. Transparency Market Re- search. 2015, pp. 2015-2023. //www.transparencymarketresearch.com/surfactants-market.html (Accessed 04/20/2017).

[3] Florence, A.T.; Attwood, D. Surfactants. In: Physicochemical Principles of Pharmacy, $4^{\text {th }}$ Edition; Pharmaceutical Press: London, 2006; pp. 177-228.

[4] Mollica, A.; Macedonio, G.; Stefanucci, A.; Constante, R.; Carradori, S.; Cataldi, V.; Di Giulio, M.; Cellini, L.; Silvestri, R.; Giordano, C.; Scipioni, A.; Morosetti, S.; Punzi, P.; Mirzaie, S. Arginine- and lysine- rich peptides: synthesis, characterization and antimicrobial activity. Lett. Drug Design Disc. 2017, 14, 1-7.

[5] Pinazo, A.; Manresa, M.A.; Marques, A.M.; Bustelo, M.; Espuny, M.J.; Pérez L. Amino acid-based surfactants: New antimicrobial agents. Adv. Colloid Interface Sci. 2016, 228, 17-39.

[6] Singh, A.; Tyagi, V.K. Arginine based novel cationic surfactants: a review. Tenside Surf. Det. 2015, 51, 202-214.

[7] Loeffler, M.; McClements, D.J.; McLandsborough, L.; Terjung, N.; Chang, Y.; Weiss, J. Electrostatic interactions of cationic lauric arginate with anionic polysaccharides affect antimicrobial activity against spoilage yeasts. J. Applied Microbiol. 2014, 117, 28-39.

[8] Pérez, L.; Pinazo, A.; Pons, R.; Infante, M.R. Gemini surfactants from natural amino acids. Adv Colloid Interface Sci. 2014, 205,134-155.

[9] Infante, M.R.; Pérez, L.; Morán, C.; Pons, R.; Pinazo, A. Synthesis, aggregation properties and applications of biosurfactants derived from arginine. In: Biobased surfactants and detergents. Synthesis, properties and applications; Hayes D.G.; Kitamoto, D.; Solaiman, D.K.Y.; Ashby, R.D. Ed., $1^{\text {st }}$ Edition; AOCS Press: Urbana, Illinois, 2009; pp. 374-380.

[10] Fait, M.E.; Garrote, G.L.; Clapés, P.; Tanco, S.E.; Lorenzo, J.; Morcelle, S.R. Biocatalytic synthesis, antimicrobial properties and toxicity studies of arginine derivative surfactants. Amino Acids. 2015, 47, 1465-1477.

[11] Obłak, E.; Piecuch, A.; Krasowska, A.; Łukzyński, J. Antifungal activity of gemini quaternary ammonium salts. Microbiol. Res. 2013, 168, 630-638.

[12] Kanjilal, S.; Sunitha, S.; Reddy, P.S.; Kumar, K.P.; Murty, U.S.N.; Prasad, R.N.B. Synthesis and evaluation of micellar properties and antimicrobial activities of imidazole-based surfactants. Eur. J. Lipid Sci. Technol. 2009, 111, 941-948.

[13] Badawi, A.M.; Mekawi, M.A.; Mohamed, A.S.; Mohamed, M.Z.; Kowdairy, M.M. Surface and biological activity of some novel cationic surfactants. J. Surfact. Det. 2007, 10, 243-255.

[14] Vieira, D.B.; Carmona-Ribeiro, A.M. Cationic lipid and surfactants as antifungal agents: mode of action. J. Antimicrob. Chem. 2006 $58,760-767$

[15] Ziani, K.; Chang, Y.; McLandsborough, L.; McClements, D.J. Influence of surfactant charge on antimicrobial efficacy of surfactant-stabilized thyme oil nanoemulsions. J. Agricultural Food Chem. 2011, 59, 6247-6255. 
[16] Murguía, M.C.; Vaillard, M.V.; Sánchez, V.G.; Di Conza, J.; Grau, R.J. Synthesis, surface-active properties, and antimicrobial activities of new double-chain gemini surfactants. J. Oleo Sci. 2008, 57, 301-308.

[17] Castillo, J.A.; Infante, M.R.; Manresa, A.; Vinardell, M.P.; Mitjans, M.; Clapés, P. Chemoenzymatic synthesis and antimicrobial and haemolytic activities of amphiphilic bis(phenylacetylarginine) derivatives. ChemMedChem. 2006, 1, 1091-1098.

[18] Brown, G.D.; Denning, D.W.; Gow, N.A.R.; Levitz, S.M.; Netea, M.G.; White, T.C. Hidden killers: Human fungal infections. Sci. Transl. Med. 2012, 4, 165 rv13.

[19] Kistler, H.C.; Alabouvette, C.; Baayen, R.P.; Bentley, S.; Brayford, D.; Coddington, A.; Correll, J.; Daboussi, M.-J.; Elias, K.; Fernandez, D.; Gordon, T.R.; Katan, T.; Kim, H.G.; Leslie, J.F.; Martyn, R.D.; Migheli, Q.; Moore, N.Y.; O’Donnell, K.; Ploetz, R.C.; Rutherford, M.A.; Summerell, B.; Waalwijk, C.; Woo, S. Systematic numbering of vegetative compatibility groups in the plant pathogenic fungus Fusarium oxysporum. Phytopathol. 1998, 88, 30-32.

[20] Lim, H.-S.; Kim, Y.-S.; Kim, S.-D. Pseudomonas stutzeri YPL-1 genetic transformation and antifungal mechanism against Fusarium solani, an agent of plant root rot. Appl. Envionm. Microb. 1991, 57, 510-516.

[21] Podila, G.P.; Rogers, L.M.; Kolattukudy, P.E. Chemical signals from avocado surface wax trigger germination and appressorium formation in Colletotrichum gloeosporioides. Plant Physiol. 1993, 103, 267-272.

[22] Balardin, R.S.; Jarosz, A.M.; Kelly, J.D. Virulence and molecular diversity in Colletotrichum lindemuthianum from South, Central, and North America. Phytopathol. 1997, 87, 1184-1191.

[23] Patiny, L.; Borel, A. ChemCalc: a building block for tomorrow's chemical infrastructure. J. Chem. Inf. Model. 2013, 53, 1223-1228.

[24] Broekaert, W.F.; Terras, F.R.G.; Cammue, B.P.A.; Vanderleyden, J. An automated quantitative assay for fungal growth inhibition. FEMS Microbiol. Lett. 1990, 69, 55-59.

[25] Ji, C.; Kuć, J. Antifungal activity of cucumber $\beta$-1,3-glucanase and chitinase. Physiol. Mol. Plant Pathol. 1996, 49, 257-265.

[26] de Freitas, C.D.T.; Lopes, J.L.S.; Beltramini, L.M.; de Oliveira, R.S.B.; Oliveira, J.T.A.; Ramos, M.V. Osmotin from Calotropis procera latex: new insights into structure and antifungal properties. Biochim. Biophys. Acta 2011, 1808, 2501-2507.

[27] Thordal-Christensen, H.; Zhang, Z.; Wei, Y.; Collinge, D.B. Subcellular localization of $\mathrm{H}_{2} \mathrm{O}_{2}$ in plants. $\mathrm{H}_{2} \mathrm{O}_{2}$ accumulation in papillae and hypersensitive response during the barley-powdery mildew interaction. Plant J. 1997, 11, 1187-1194.

[28] Pereira, F.O.; Wanderley, P.A.; Viana, F.A.C.; de Lima, R.B.; de Sousa, F.B.; dos Santos, S.G.; Lima, E.O. Effects of Cymbopogon winterianus Jowitt ex Bor essential oil on the growth and morpho- genesis of Trichophyton mentagrophytes. Brazilian J. Pharm. Sci. 2011, 47, 145-153.

[29] Santos, D.A.; Barros, M.E.S.; Hamdan, J.S. Establishing a method of inoculum preparation for susceptibility testing of Trichophyton rubrum and Trichophyton mentagrophytes. J. Clin. Microbiol. 2006, 44, 98-101.

[30] Barchiesi, F.; Arzeni, D.; Camiletti, V.; Simonetti, O.; Cellini, A.; Offidani, A.M.; Scalise, G. In vitro activity of posaconazole against clinical isolates of dermatophytes. J. Clin. Microbiol. 2001, 39 , 4208-4209.

[31] Santos, D.; Hamdan, J.S. Evaluation of broth microdilution antifungal susceptibility testing conditions for Trichophyton rubrum. J. Clin. Microbiol. 2005, 43, 1917-1920.

[32] Morán, M.C.; Clapés, P.; Comelles, F.; García, T.; Pérez, L.; Vinardell, P.; Mitjans, M.; Infante, M.R. Chemical structure/property relationship in single-chain arginine surfactants. Langmuir. 2001, 17, 5071-5075.

[33] Huang, M.; Hebert, A.S.; Coon, J.J.; Hull, C.M. Protein composition of infectious spores reveals novel sexual development and germination factors in Cryptococcus. PLoS Genet 2015, 11 e1005490.

[34] Chitarra, G.S.; Breeuwer, P.; Nout, M.J.R.; van Aelst, A.C.; Rombouts, F.M.; Abee, T. An antifungal compound produced by Bacillus subtilis YM 10-20 inhibits germination of Penicilliumroqueforticonidiospores. Journal of Applied Microbiology. 2003, 94, 159166.

[35] Mesquita, N.; Portugal, A.; Piñar, G.; Loureiro, J.; Coutinho, A.P.; Trovão, J.; Nunes, I.; Botelho, M.L.; Freitas, H. Flow cytometry as a tool to assess the effects of gamma radiation on the viability, growth and metabolic activity of fungal spores. Int. Biodeterior. Biodegradation. 2013, 84, 250-257.

[36] Carmona-Ribeiro, A.M.; Carrasco, L.D.M. Fungicidal assemblies and their mode of action. OA Biotechnology. 2013, 2, 25.

[37] Vieira, O.V.; Hartmann, D.O.; Cardoso, C.M.P.; Oberdoerfer, D.; Baptista, M.; Santos, M.A.S.; Almeida, L.; Ramalho-Santos, J.; Vaz, W.L.C. Surfactants as microbicides and contraceptive agents: a systematic in vitro study. PLOS ONE. 2008, 3, e2913.

[38] Nakata, K.; Tsuchido, T.; Matsumura, Y. Antimicrobial cationic surfactant, cetyltrimethylammonium bromide, induces superoxide stress in Escherichia coli cells. J. Appl. Microbiol. 2010, 110, 568579.

[39] Yu, Q.; Zhang, B.; Ma, F.; Jia, C.; Xiao, C.; Zhang, B.; Xing, L.; Li, M. Novel mechanisms of surfactants against Candida albicans growth and morphogenesis. Chemico-biological Interact. 2015, 227, 1-6.

[40] Nordberg, J.; Arnér, E.S.J. Reactive oxygen species, antioxidants, and the mammalian thioredoxin system. Free Radic. Biol. Med. 2001, 31, 1287-1312. 